\title{
Clinical Factors for Predicting Neurophysiological Improvements Upon Extension and Flexion in Cervical Spondylotic Myelopathy Patients: A Retrospective Cohort Study
}

\section{Zhengran Yu}

Sun Yat-sen University First Affiliated Hospital

Jiacheng Chen

Sun Yat-sen University First Affiliated Hospital

Xing Cheng

Sun Yat-sen University First Affiliated Hospital

\section{Zhiyuan Zou}

Sun Yat-sen University First Affiliated Hospital

Dingxiang Xie

Sun Yat-sen University First Affiliated Hospital

Yuguang Chen

Sun Yat-sen University First Affiliated Hospital

\section{Xuenong Zou}

Sun Yat-sen University First Affiliated Hospital

Xinsheng Peng ( $\sim$ pengxs66@yahoo.com)

Sun Yat-sen University First Affiliated Hospital https://orcid.org/0000-0002-6192-5635

\section{Research}

Keywords: Cervical spondylotic myelopathy, Dynamic somatosensory evoked potential, Improvement upon cervical extension or flexion, Magnetic resonance imaging, Plain cervical lateral radiograph

Posted Date: March 23rd, 2021

DOI: https://doi.org/10.21203/rs.3.rs-324536/v1

License: (c) (i) This work is licensed under a Creative Commons Attribution 4.0 International License. Read Full License 


\section{Abstract}

Background

Cervical extension and flexion are generally thought to be harmful to CSM patients. Contrary to previous notions, a proportion of CSM patients presented DSSEP improvement upon extension and/or flexion. This study aims to determine the prediction criteria for DSSEP improvement upon extension and flexion with clinical and neutralposition imaging.

\section{Methods}

CSM patients between 2015 and 2019 were retrospectively evaluated. The recorded outcomes were DSSEP changes upon extension and flexion, disease duration, modified Japanese Orthopedic Association (mJOA) score, gait impairment presence, weakness of upper limb muscles, and positive Hoffmann sign designation. The collection of MRI data included the compression ratio, the number of stenotic levels, the Mühle stenosis grade and disc degeneration stage of the most severe segment, and the presence of ligamentum flavum hypertrophy and intramedullary T2WI hyperintensity. Cervical alignment types were evaluated on plain cervical lateral radiographs.

Results

Forty-nine patients were finally enrolled. Nine (18.4\%) and 11 (22.4\%) patients showed DSSEP improvement upon extension and flexion, respectively. Logistic regression analysis showed that an involved segment number $\leq 2$ $(P=0.018)$ and a straight/sigmoid cervical alignment $(P=0.033)$ were significant criteria for predicting DSSEP improvement upon extension (probability: 85.7\%). Mühle grade $3(P=0.022)$ and disease duration $\leq 6$ months $(P=0.04)$ were significant criteria for predicting improvement upon flexion (probability: $85.7 \%)$.

\section{Conclusions}

Cervical extension and flexion might not necessarily cause deterioration and can even improve some CSM patients' neurological function at DSSEP examination. The involved segment number and cervical alignment were related to extension DSSEP improvement, while the stenosis grade and disease durations were related to flexion improvement. Our work suggests potential significance of educating CSM patients on maintaining individualized neck positions based on their clinical and radiographic findings.

BaTrial registration

The trial was retrospectively registered on April 30th, 2020 and the registration number is "[2020]151".

\section{Introduction}

The static and dynamic narrowing of the cervical canal is one of the most important factors that causes cervical spondylotic myelopathy (CSM). [1, 2] Cervical motions could rapidly alter (improve or worsen) cervical and referred symptoms, depending on the direction of end-range positioning or of repetitive end-range testing of cervical spine movements.[3] Somatosensory evoked potential (SSEP) is an objective neurophysiological test widely used in evaluating neurological functions and predicting prognosis in CSM.[4] In our previous studies[5, 6], we found most patients had dynamic SSEP (DSSEP) deteriorated upon extension and flexion, as other studies suggested [7]. For those patients, their DSSEP N13 amplitude ratios correlated with preoperative mJOA scores and postoperative recovery rates, as well as compressive degrees of the spinal cord in axial MRI and cervical segmental instability in 
dynamic X-ray.[6] More severely compressed spinal cord and unstable canal structures rendered smaller DSSEP N13 amplitude ratios, i.e. worse dynamic neurological compensatory capacities.[6] However, there were some CSM patients presented significantly improved DSSEP amplitudes and/or latencies during cervical spine flexion and/or extension, whose DSSEP N13 amplitude ratios were obviously unmatched with their MRI compression degrees.[5, 6] These patients also frequently presented symptomatic alleviations at extension or flexion. The reasons why patients presented abnormal DSSEP upon extension and/or flexion positions are still not clear.

It has been reported that cervical extension shortens and widens the cervical cord, but diminishes canal spaces and worsens the medullary compression visible on dynamic MRI.[8, 9] On the other hand, although the spinal canal diameter could increase in flexion, the stretching forces applied to the spinal cord could also increase longitudinal tension, and cause ventral spinal cord compression against osteophytes and discs - worsening an eventual ventral compression at this position[10]. Based on our previous finding on the correlations between DSSEPS and radiographic results, we expanded our sample size and separated extension- or flexion-DSSEP improved patients away from others, in order to investigate the commonalities of CSM patients with improved neurological function upon extension and flexion respectively, and to determine prediction criteria for extension- or flexion-DSSEP improvements with clinical and neutral-position imaging.

\section{Methods}

\section{Patient cohort}

This single-center retrospective study included consecutive CSM patients at our department with preoperative DSSEP and MRI tests between 2015 and 2019.

The Human Ethics Committee of the First Affiliated Hospital of Sun Yat-sen University approved the trial (Ethics number: [2020]151), and each patient provided informed consent.

Patients with a previous surgical or trauma history, spinal tumor, or peripheral neurological disease were excluded. The demographic data collected included sex, age and critical comorbidities. Thirty-eight subjects overlapped with our prior report[6], which evaluated correlations between amplitude ratios of DSSEP and MRI measurements. The CSM disease duration (i.e., time from the onset of CSM-related neurological signs) and modified Japanese Orthopedic Association (mJOA) score [11] for each patient at the time of DSSEP tests were recorded. Other clinical signs, including gait impairment, upper limb weakness and atrophy, and the Hoffmann sign, were also documented.

\section{Realization and measurement of DSSEP}

An electrophysiological monitoring system (Nicolet Endeavor CR) was used to elicit and record the DSSEPs. Median and ulnar nerve DSSEPs were examined using established methods described in our previous study. [6, 12] Recording electrodes were placed over the spinous process of the 2nd cervical vertebra (C2S), the contralateral parietal cortex (Cc) and forehead reference site (Fz) regions of the scalp, and Erb's points ipsilateral (EPi) and contralateral (EPC) to the stimulation. [13] The DSSEP waves for each recording montage, labeled EPi-EPc, C2S-EPc, and $\mathrm{Cc}-\mathrm{Fz}$, were recorded as N9, N13, and N20, respectively. We adopted N9 as the standard reference channel. When N9 was unidentifiable or poorly reproducible, the existence of peripheral nerve pathology was suspected. The DSSEPs were measured upon a neutral neck position first. Patients were then tested with neck positions at approximately $35^{\circ}$ flexion, followed by approximately $20^{\circ}$ extension of the cervical spine, using a device for elevating the head and neck with minimal discomfort to the subject (Fig. 1). To confirm the reproducibility of the DSSEPs, each measurement was carried out at least three times by a spine surgeon and two electrophysiologists. 
We compared the same patient's median nerve SSEP upon extension or flexion with those in the neutral position. A DSSEP improvement upon extension or flexion was defined as a shortened N13 or N20 latency exceeding 2.5 SD of that at neutral position (which were 1.78 ms for N13 and 2.01 ms for N20 in this study); or increased N13 or N20 amplitude exceeding 20\% compared with the patient's SSEP in the neutral position. We defined an immeasurable SSEP as a waveform that could not be identified by averaging over 500 sweeps. Any measurable SSEP waveform would be considered a DSSEP improvement compared with an immeasurable SSEP waveform. Patients with improved DSSEP upon extension or flexion was classified into the extension-improved (EI) or flexion-improved (FI) groups respectively. Otherwise, the patients were classified into the extension-nonimproved (EN) or flexionnonimproved (FN) group.

\section{Imaging methods and analysis protocol}

All MR examinations were performed with a 3.0-T MR imager (Siemens Trio) with the patients lying in the supine position on a spine-array coil. The authors evaluated compressed spinal cords using standard imaging sequences.

Qualitative MRI features on sagittal T2-weighted sequences included the presence of cervical ligamentum flavum hypertrophy (LFH) and cord intramedullary T2WI signal hyperintensity (IHI). LFH is defined as a thickened ligamentum flavum compared with the thickness of adjacent segments, with a loss of epidural fat tissue and dural sac compression. [14]

Quantitative MRI features on T2-weighted sequences included the compression ratio(CR), which was obtained via dividing sagittal diameter by transverse diameter of the cord at the most compressed site[6], the number of stenotic segments, cervical stenosis grade (classification of Mühle et al.[15], Grade 0 to 3) and disc degeneration grade (classification of Miyazaki et al.[16], Grade 1 to 5) of the most compressed segment.

The cervical alignment types were measured on plain cervical lateral radiographs and categorized into one of the following four groups according to the modified Toyama method[17] (Fig. 2).

These measurements were carried out by 3 independent investigators.

\section{Statistical analysis}

Age, CSM disease duration and mJOA score differences between the El/FI and EN/FN groups were calculated with Student's T-test. The differences in DSSEP changes upon flexion, cervical alignment types, ligamentum flavum hypertrophy and intramedullary intensity between the El/FI and EN/FN groups were calculated with chi-square tests. The numbers of stenotic segments, Mühle stenosis grade and disc degeneration stage between these groups were compared with the Kruskal-Wallis method.

With regard to clinical and MR imaging criteria that predict DSSEP improvement upon extension or flexion, the following criteria were evaluated: disease duration no more than 6 months, no more than 2 stenotic levels, straight or sigmoid cervical alignment, and Mühle grade 3 stenosis.

Bivariate analysis was used to evaluate the relationship between DSSEP improvement upon extension or flexion and a set of clinical and radiographic criteria of interest. Variables with $p<0.2$ in the bivariate analysis were entered into a forward stepwise multivariate logistic regression model. Model fit was assessed with the Omnibus tests of model coefficients and Hosmer-Lemeshow goodness of fit test. A significant value for the Omnibus chi-square test indicates a credible improvement of the new model over the baseline model, and a non-significant value for the Hosmer-Lemeshow chi-square test suggests an absence of biased fit. After the final logistic model was performed, 
the probability of DSSEP improvement upon extension or flexion was calculated. The statistical software $R(R$ version 3.6.1) was used for statistical analysis.

\section{Results}

\section{Demographic and clinical results in each group}

Forty-nine CSM patients (55.8 \pm 11.3 years; 28 men) were included in this study. Nine (18.4\%) patients had DSSEPS improved upon extension, and eleven (22.4\%) upon flexion. Obviously, the El group's extension DSSEP N13 amplitude ratios were significantly higher than the EN group (T-test, $\mathrm{p}<0.001$ ), but the two groups' flexion DSSEP N13 amplitude ratios did not vary. The FI group had significantly higher flexion DSSEP N13 amplitude ratios(T-test, $p<0.001$ ), but its extension DSSEP N13 amplitude ratios did not change compared with the FN group. The El group patients had significantly shorter disease duration ( $T$-test, $p=0.024$ ) than patients in EN group. No differences were found between the EI and EN groups with respect to sex, age, mJOA score, gait impairment, upper limb weakness, or positive Hoffmann signs. No statistically significant differences were found for any demographic or clinical data between the FI and FN groups. (Table 1) 
Table 1

Comparison of Each Group with respect to Demographic, DSSEP, and clinical features

\begin{tabular}{|c|c|c|c|c|c|c|c|}
\hline \multirow[t]{2}{*}{ Group } & \multicolumn{3}{|c|}{ DSSEP change upon extension } & \multicolumn{3}{|c|}{ DSSEP change upon flexion } & \multirow{2}{*}{$\begin{array}{l}\text { Statistical } \\
\text { method }\end{array}$} \\
\hline & $\begin{array}{l}\text { Extension- } \\
\text { Improved } \\
\text { (El) }\end{array}$ & $\begin{array}{l}\text { Extension- } \\
\text { Non- } \\
\text { improved(EN) }\end{array}$ & $\mathbf{P}$ & $\begin{array}{l}\text { Flexion- } \\
\text { Improved } \\
\text { (FI) }\end{array}$ & $\begin{array}{l}\text { Flexion-Non- } \\
\text { improved(FN) }\end{array}$ & $\mathbf{P}$ & \\
\hline No.(\%) & 9 (18.4\%) & $40(81.6 \%)$ & & $11(22.4 \%)$ & $38(77.6 \%)$ & & \\
\hline $\begin{array}{l}\text { Sex male } \\
\text { (female) }\end{array}$ & $3(6)$ & $25(15)$ & 0.221 & $5(6)$ & $23(15)$ & 0.587 & $\begin{array}{l}\text { Chi- } \\
\text { square }\end{array}$ \\
\hline $\begin{array}{l}\text { Age (mean } \\
\pm \text { SD) }\end{array}$ & $\begin{array}{l}58.56 \pm \\
12.77\end{array}$ & $55.2 \pm 11.27$ & 0.445 & $\begin{array}{l}59.91 \pm \\
10.88\end{array}$ & $54.63 \pm 11.57$ & 0.193 & T-test \\
\hline $\begin{array}{l}\text { Extension } \\
\text { DSSEP N13 } \\
\text { amplitude } \\
\text { ratio }\end{array}$ & $\begin{array}{l}1.33 \pm \\
0.16\end{array}$ & $0.72 \pm 0.20$ & 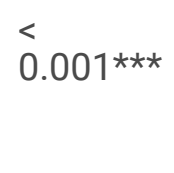 & $\begin{array}{l}0.96 \pm \\
0.47\end{array}$ & $0.79 \pm 0.22$ & 0.104 & T-test \\
\hline $\begin{array}{l}\text { Flexion } \\
\text { DSSEP N13 } \\
\text { amplitude } \\
\text { ratio }\end{array}$ & $\begin{array}{l}1.23 \pm \\
0.40\end{array}$ & $0.85 \pm 0.26$ & 0.132 & $\begin{array}{l}1.29 \pm \\
0.06\end{array}$ & $0.76 \pm 0.23$ & 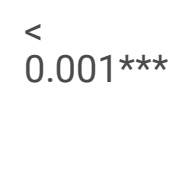 & T-test \\
\hline $\begin{array}{l}\text { CSM } \\
\text { disease } \\
\text { duration } \\
\text { (months) }\end{array}$ & $\begin{array}{l}11.44 \pm \\
10.57\end{array}$ & $30.28 \pm 29.30$ & $0.024^{*}$ & $\begin{array}{l}15.82 \pm \\
16.79\end{array}$ & $30.01 \pm 29.49$ & 0.142 & T-test \\
\hline mJOA & $\begin{array}{l}14.56 \pm \\
1.50\end{array}$ & $14.9 \pm 1.83$ & 0.565 & $\begin{array}{l}14.09 \pm \\
1.50\end{array}$ & $15.05 \pm 1.79$ & 0.119 & T-test \\
\hline $\begin{array}{l}\text { Gait } \\
\text { impairment } \\
\text { Yes(No) }\end{array}$ & $4(5)$ & $22(18)$ & 0.295 & $8(3)$ & $18(20)$ & 0.254 & $\begin{array}{l}\text { Chi- } \\
\text { square }\end{array}$ \\
\hline $\begin{array}{l}\text { Upper limb } \\
\text { weakness } \\
\text { Yes(No) }\end{array}$ & $4(5)$ & $22(18)$ & 0.719 & $6(5)$ & $20(18)$ & 1 & $\begin{array}{l}\text { Chi- } \\
\text { square }\end{array}$ \\
\hline $\begin{array}{l}\text { Hoffmann } \\
\text { sign } \\
\text { (Yes/No) }\end{array}$ & $6(3)$ & $12(28)$ & 0.425 & $8(3)$ & $16(22)$ & 0.148 & $\begin{array}{l}\text { Chi- } \\
\text { square }\end{array}$ \\
\hline$* p<0.05$ & & & & & & & \\
\hline
\end{tabular}

\section{Comparison of the radiographic characteristics of each group}

The CR of all patients was $6.52 \pm 1.74 \mathrm{~mm}$, and did not varied between the El and EN, or FI and FN group. Patients in the El group had significantly fewer stenotic segments (Kruskal-Wallis, $p<0.001$ ) than those in the EN group, while patients in the Fl group had significantly more severe Mühle stenosis grades (Kruskal-Wallis, $p=0.038$ ) than those in the FN group. The El group patients also tended to have absent LFH (Chi-square, $p=0.128)$ and IHI (Chi-square, $p=$ 0.163), and lower disc degeneration grade (Kruskal-Wallis, $p=0.182$ ) compared with the EN group, although not statistically different. Seventeen, 13, 7 and 12 patients were classified as cervical lordotic, straight, sigmoid and kyphotic, respectively. Patients in the El group mainly presented straight and sigmoid cervical alignment, whereas 
patients in the EN group mainly presented lordotic or kyphotic alignment (chi-squared, $p=0.005$ ). More detailed data are shown in Table 2.

Table 2

Comparison of Groups with Respect to MRI Characteristics

\begin{tabular}{|c|c|c|c|c|c|c|c|}
\hline \multirow[t]{2}{*}{ Group } & \multicolumn{3}{|c|}{ DSSEP change upon extension } & \multicolumn{3}{|c|}{ DSSEP change upon flexion } & \multirow{2}{*}{$\begin{array}{l}\text { Statistical } \\
\text { method }\end{array}$} \\
\hline & $\begin{array}{l}\text { Extension- } \\
\text { Improved } \\
\text { (EI) }\end{array}$ & $\begin{array}{l}\text { Extension- } \\
\text { Non- } \\
\text { improved } \\
(\text { EN) }\end{array}$ & $\mathbf{P}$ & $\begin{array}{l}\text { Flexion- } \\
\text { Improved } \\
\text { (FI) }\end{array}$ & $\begin{array}{l}\text { Flexion- } \\
\text { Non- } \\
\text { improved } \\
\text { (FN) }\end{array}$ & $\mathbf{P}$ & \\
\hline Compression ratio & $\begin{array}{l}0.38 \pm \\
0.10\end{array}$ & $\begin{array}{l}0.38 \pm \\
0.09\end{array}$ & 0.918 & $\begin{array}{l}0.36 \pm \\
0.08\end{array}$ & $0.39 \pm 0.09$ & 0.453 & T-test \\
\hline $\begin{array}{l}\text { Ligamentum } \\
\text { flavum hypertrophy } \\
\text { (Yes/No) }\end{array}$ & $3(6)$ & $27(13)$ & 0.128 & $7(4)$ & 23(15) & 1 & $\begin{array}{l}\text { Chi- } \\
\text { square }\end{array}$ \\
\hline $\begin{array}{l}\text { Intramedullary } \\
\text { T2WI } \\
\text { hyperintensity } \\
\text { (Yes/No) }\end{array}$ & $4(5)$ & $30(10)$ & 0.163 & $7(4)$ & $27(11)$ & 0.9215 & $\begin{array}{l}\text { Chi- } \\
\text { square }\end{array}$ \\
\hline $\begin{array}{l}\text { No. Involved } \\
\text { segments (mean } \pm \\
\text { SD) }\end{array}$ & $\begin{array}{l}1.56 \pm \\
0.68\end{array}$ & $\begin{array}{l}2.95 \pm \\
1.09\end{array}$ & $<.001^{\star \star *}$ & $\begin{array}{l}2.27 \pm \\
1.05\end{array}$ & $2.82 \pm 1.17$ & 0.269 & $\begin{array}{l}\text { Kruskal- } \\
\text { Wallis }\end{array}$ \\
\hline $\begin{array}{l}\text { Disc degeneration } \\
\text { grade (mean } \pm S D \text { ) }\end{array}$ & $\begin{array}{l}3.56 \pm \\
1.17\end{array}$ & $\begin{array}{l}4.13 \pm \\
0.90\end{array}$ & 0.182 & $\begin{array}{l}3.91 \pm \\
1.08\end{array}$ & $4.05 \pm 0.94$ & 0.752 & $\begin{array}{l}\text { Kruskal- } \\
\text { Wallis }\end{array}$ \\
\hline $\begin{array}{l}\text { Mühle stenosis } \\
\text { grade (mean } \pm \text { SD) }\end{array}$ & $\begin{array}{l}2.44 \pm \\
0.68\end{array}$ & $2.2 \pm 0.75$ & 0.372 & $\begin{array}{l}2.64 \pm \\
0.64\end{array}$ & $2.13 \pm 0.73$ & $0.0384^{*}$ & $\begin{array}{l}\text { Kruskal- } \\
\text { Wallis }\end{array}$ \\
\hline $\begin{array}{l}\text { Cervical alignment } \\
\text { (Lordosis/Straight/ } \\
\text { Sigmoid/Kyphosis) }\end{array}$ & $1 / 4 / 4 / 0$ & $16 / 9 / 3 / 12$ & $0.005^{\star \star}$ & $3 / 3 / 3 / 2$ & $14 / 10 / 4 / 10$ & 0.545 & $\begin{array}{l}\text { Chi- } \\
\text { square }\end{array}$ \\
\hline \multicolumn{8}{|c|}{${ }^{*} p<0.05 ; * \star p<0.01 ; * \star \star p<0.001$} \\
\hline
\end{tabular}

\section{Clinical and MRI criteria for prediction of DSSEP improvement upon extension and flexion}

Based on the findings above, we picked 6 clinical and radiographic indicators of potential significance in predicting DSSEP improvement upon extension ( $p<0.2$, i.e. CSM disease duration, the presence of $\mathrm{LFH}$ and IHI, the number of involved segments, disc degeneration grade, and cervical alignment types). We then divided patients into groups according to the following 6 dichotomous criteria: disease duration $\leq 6$ months, stenotic levels $\leq 2$, straight or sigmoid cervical alignment, disc degeneration grade $\leq 3$, absence of LFH, and absence of IHI. All the 6 criteria (chisquare, $\mathrm{P}<0.2)$ were entered into a forward stepwise multivariate logistic regression model for predicting DSSEP improvement at extension. (Table 3$)$ The stenotic levels $\leq 2(\mathrm{OR}=15.711 ; 95 \% \mathrm{Cl}$ : $1.6-154.232, \mathrm{P}=0.018)$ and straight or sigmoid cervical alignment $(\mathrm{OR}=12.275 ; 95 \% \mathrm{Cl}$ : $1.229-122.587, \mathrm{P}=0.033)$ were significant criteria for predicting DSSEP improvement upon extension. The two-step regression model (Omnibus test, $\chi^{2}=17.560, P<$ 0.001; Hosmer-Lemeshow test, $\chi^{2}=0.206, P=0.902$ ) could predict $85.7 \%$ of the cases. (Table 4 ) 
Table 3

Chi-square and Univariate Logistic Regression Analysis of Dichotomous Criteria for DSSEP improvement upon extension and flexion

\section{DSSEP change upon extension}

\begin{tabular}{|c|c|c|c|c|c|c|c|}
\hline & $\begin{array}{l}\text { El Group } \\
\text { Yes(No) }\end{array}$ & $\begin{array}{l}\text { EN Group } \\
\text { Yes(No) }\end{array}$ & $\begin{array}{l}\chi 2 \mathrm{p} \\
\text { value }\end{array}$ & $\begin{array}{l}\text { Logit } \\
\text { Coefficient } \\
\text { B }\end{array}$ & $\begin{array}{l}\text { Standard } \\
\text { Error }\end{array}$ & $\begin{array}{l}\text { Logit P } \\
\text { Value }\end{array}$ & $\begin{array}{l}\text { Odds Ratio } \\
(95 \% \mathrm{Cl})\end{array}$ \\
\hline $\begin{array}{l}\text { Disease Duration } \\
\leq 6 \text { months }\end{array}$ & $6(3)$ & $9(31)$ & $0.028 *+$ & 1.93 & 0.802 & $0.016 *$ & $\begin{array}{l}6.889 \\
(1.43- \\
33.182)\end{array}$ \\
\hline $\begin{array}{l}\text { Stenotic segment } \\
\text { number } \leq 2\end{array}$ & $8(1)$ & $14(26)$ & $0.0103^{\star \dagger}$ & 2.698 & 1.111 & $0.015^{\star}$ & $\begin{array}{l}14.857 \\
(1.683- \\
131.171)\end{array}$ \\
\hline $\begin{array}{l}\text { Straight or } \\
\text { sigmoid } \\
\text { alignment }\end{array}$ & $8(1)$ & $12(28)$ & $0.0041 *{ }^{\dagger}$ & 2.927 & 1.115 & $0.009 * \star$ & $\begin{array}{l}18.667 \\
(2.097- \\
166.139)\end{array}$ \\
\hline $\begin{array}{l}\text { Disc degeneration } \\
\text { grade } \leq 3\end{array}$ & $5(4)$ & 10(30) & $0.163^{\dagger}$ & 1.322 & 0.764 & 0.084 & $\begin{array}{l}0.267 \\
(0.06- \\
1.191)\end{array}$ \\
\hline Absence of LFH & $6(3)$ & 13(27) & $0.128^{\dagger}$ & 1.424 & 0.784 & 0.069 & $\begin{array}{l}0.241 \\
(0.052- \\
1.118)\end{array}$ \\
\hline Absence of IHI & $5(4)$ & $10(30)$ & $0.163^{\dagger}$ & 1.322 & 0.764 & 0.084 & $\begin{array}{l}0.267 \\
(0.06- \\
1.191)\end{array}$ \\
\hline \multicolumn{8}{|c|}{ DSSEP change upon flexion } \\
\hline & $\begin{array}{l}\text { FI Group } \\
\text { Yes(No) }\end{array}$ & $\begin{array}{l}\text { FN Group } \\
\text { Yes(No) }\end{array}$ & $\begin{array}{l}\chi 2 \mathrm{p} \\
\text { value }\end{array}$ & $\begin{array}{l}\text { Logit } \\
\text { Coefficient } \\
\text { B }\end{array}$ & $\begin{array}{l}\text { Standard } \\
\text { Error }\end{array}$ & $\begin{array}{l}\text { Logit P } \\
\text { Value }\end{array}$ & $\begin{array}{l}\text { Odds Ratio } \\
(95 \% \mathrm{Cl})\end{array}$ \\
\hline $\begin{array}{l}\text { Disease duration } \\
\leq 6 \text { months }\end{array}$ & $6(5)$ & $9(29)$ & $0.1131+$ & 1.352 & 0.716 & 0.059 & $\begin{array}{l}3.867 \\
(0.951- \\
15.724)\end{array}$ \\
\hline $\mathrm{mJOA}<15$ & $7(4)$ & $14(24)$ & 0.2167 & 1.099 & 0.711 & 0.122 & $\begin{array}{l}0.333 \\
(0.083- \\
1.344)\end{array}$ \\
\hline Hoffmann sign & $8(3)$ & $16(22)$ & $0.148^{\dagger}$ & 0.771 & 0.707 & 0.275 & $\begin{array}{l}2.162 \\
(0.541- \\
8.635)\end{array}$ \\
\hline Mühle grade 3 & $8(3)$ & $13(25)$ & $0.0539^{\dagger}$ & 1.635 & 0.758 & $0.031^{*}$ & $\begin{array}{l}5.128 \\
(1.160- \\
22.676)\end{array}$ \\
\hline
\end{tabular}

* $p<0.05 ; * * p<0.01$

${ }^{+}$Variables with $p<0.2$ in the bivariate analysis were entered into the forward stepwise multivariate logistic regression models.

DSSEP: dynamic somatosensory evoked potential; IHI: intramedullary T2WI hyperintensity; LFH: ligamentum flavum hypertrophy; mJOA: modified Japanese Orthopedic Association 
Table 4

Variables in the forward logistic regression equation after deletion of insignificant independent variables and other confounding variables

\begin{tabular}{|c|c|c|c|c|}
\hline \multicolumn{5}{|l|}{ DSSEP upon Extension } \\
\hline & Logit Coefficient B & Standard Error & P Value & Odds Ratio (95\% Cl) \\
\hline Straight or sigmoid alignment ${ }^{\dagger}$ & 2.754 & 1.165 & $0.018 *$ & $15.711(1.6-154.232)$ \\
\hline Stenotic segment number $\leq 2^{\ddagger}$ & 2.508 & 1.174 & $0.033^{*}$ & $12.275(1.229-122.587)$ \\
\hline \multicolumn{5}{|l|}{ DSSEP upon Flexion } \\
\hline & Logit Coefficient B & Standard Error & P Value & Odds Ratio (95\% Cl) \\
\hline Mühle grade $3 \S$ & 1.913 & 0.837 & $0.022 *$ & $6.771(1.313-34.92)$ \\
\hline Disease duration $\leq 6$ months & 1.679 & 0.815 & $0.04^{\star}$ & $5.358(1.084-26.494)$ \\
\hline \multicolumn{5}{|l|}{$\star p<0.05$} \\
\hline \multicolumn{5}{|c|}{${ }^{\dagger}$ For the variable entered in step 1 , the predicted probability of step 1 is $81.6 \%$; } \\
\hline \multicolumn{5}{|c|}{${ }^{\ddagger}$ For the variable entered in step 2 , the final predicted probability of step 2 is $85.7 \%$; } \\
\hline \multicolumn{5}{|c|}{$\S$ For the variable entered in step 1 , the predicted probability of step 1 is $77.6 \%$; } \\
\hline
\end{tabular}

Similarly, we divided patients into groups according to the following 4 dichotomous criteria: disease duration $\leq 6$ months, mJOA < 15, positive Hoffmann sign, and Mühle grade 3 stenosis. Except for mJOA $<15$, the remained 3 criteria (chi-square, $\mathrm{P}<0.2$ ) were entered into the regression model for predicting DSSEP improvement at flexion. (Table 3) The Mühle grade 3 stenosis $(\mathrm{OR}=6.771 ; 95 \% \mathrm{Cl}: 1.313-34.92 ; \mathrm{P}=0.022)$ and disease duration $\leq 6$ months $(\mathrm{OR}=5.358 ; 95 \% \mathrm{Cl}: 1.084-26.494 ; \mathrm{P}=0.04)$ were significant criteria predicting DSSEP improvement upon flexion. The two-step regression model (Omnibus test, $\chi^{2}=9.781, P=0.008$; Hosmer-Lemeshow test, $\chi^{2}=2.939, P=0.230$ ) could predict $85.7 \%$ of the cases. (Table 4 )

\section{Discussion}

To the best of our knowledge, this is the first cohort study to report neurophysiological improvement upon dynamic positions among CSM patients, and to identify clinical and radiographic factors related to neurological improvements upon cervical extension and flexion.

Currently, prolonged extension and flexion are commonly recognized as deleterious activities for CSM patients.[18] Cervical extensions make the ligamentum flavum bulging inward, decrease the dorsal subarachnoid space[19] and increase Mühle stenosis grade.[20] On the other hand, cervical flexions increase the longitudinal strain of the cord and induce compression against ventral spondylotic bar.[9, 21, 22] This was in line with our previous[6] and current finding that most patients had decreased DSSEP at both extension and flexion. However, we also found 9 (18.4\%) patients had significant DSSEP improvement upon extension, and 11 (22.4\%) had significant improvement upon flexion in the current study, demonstrating that the extended and flexed position could relieve patients' neurological deficits in some cases. Interestingly, many patients in the El group reported their preference of activities requiring 
neck extension, such as badminton and some types of gymnastics, whereas patients in the FI group usually felt more comfortable at flexion, suggesting the consistency between symptomatic and DSSEP changes. Age, duration of symptoms and baseline mJOA score were reported to be significant predictors for CSM outcomes.[23] In this study, although patients in the El groups exhibited no difference in age, sex, mJOA scores, or several other clinical signs and symptoms compared with those in the EN group, they had significantly shorter disease durations. This can be explained by that newly emerged spinal cord impingements are generally more easily reversible than those of patients suffering from long-standing compression at dynamic neck positions.

Regarding the radiographic characteristics, the $\mathrm{CR}$ were similar between the $\mathrm{El}$ and $\mathrm{EN}$ groups, or the $\mathrm{FI}$ and $\mathrm{FN}$ groups, indicating the correlations between the percent change of DSSEP amplitude ratios and the spinal cord compression degrees described in our previous study[6] were not suitable for these DSSEP-improved patients. We found the number of involved segments and cervical alignment types were significantly different between the El and EN groups in this study. Further Logistic regression analysis found that an involved-segment number $\leq 2$ was a significant criterion for predicting DSSEP improvement upon extension. Dynamic MRI studies revealed that for patients with multiple involved segments, many of the segments that were not significantly compressed in the neutral position could narrow greatly upon extension.[2, 9, 24] Thus, patients with multilevel stenosis would suffer more serious neurological deterioration upon extension, probably due to significantly less compensative space resulting from multiple segmental pincer effects, as our dynamic MRI for a patient with deteriorated flexion DSSEP shows(Fig. 3). On the contrary, fewer segments usually cause focal and limited compression and leave more compensatory space, making the patient's neurological deficits more easily relieved upon extension. El patients also tended to have straight or sigmoid cervical alignments, which is another significant criterion for predicting DSSEP improvement upon extension. For CSM patients with these two alignment types, their cervical cords were usually tightly longitudinally stretched and suffered from focal anterior compression, such as protruding discs or osteophytes from focal kyphosis in the neutral position. During extension, their cervical cords could be longitudinally relaxed and draped backward, thus ameliorating the stretching tension and the anterior compression to some extent,[9] as our dynamic MRI for a patient with improved extension DSSEP shows(Fig. 4). Lordotic patients will not experience such benefits because their cords are already longitudinally relaxed in their neutral positions.[2] Kyphotic patients experienced much more severe potential ligamentum flavum bulges and pincer effects upon extension, [25-27] which could offset the benefits of decreased longitudinal tension.

In addition, disease duration $\leq 6$ months is a significant predictive criterion for DSSEP improvement upon flexion. The rationale is the same as that mentioned above, i.e., that new spinal cord impingements were more restorative and reversible once the compression status changed. Besides, the Mühle stenosis grade in the FI group was significantly greater (Kruskal-Wallis, $p<0.05$ ), and the grading of Mühle grade 3 is a significant criterion for predicting DSSEP improvement upon flexion. Mounting evidence has shown that CSM patients could have expanded cervical canal, even with cord decompression on flexion MRI.[8, 9, 24, 28] The diameter of the dorsal subarachnoid space at each level from C2 to C7 could increase up to $89 \%$ in flexion.[19] According to those dynamic MRI results, the severely compressed Muhle grade 3 patients at neutral MRI could probably enjoy more benefits from spinal canal enlargement upon flexion, and thus are more likely to present DSSEP improvement upon flexion.

\section{Conclusions}

In conclusion, our data indicate that the extended and flexed neck positions could relieve CSM patients' electrophysiological deficits in some cases. Statistically, we found that involved-segment number $\leq 2$ and straight or sigmoid cervical alignment are significant in predicting the improvement of DSSEPs upon extension, while the

Page $10 / 17$ 
Mühle grade 3 and disease duration $\leq 6$ months are significant for DSSEP improvement upon flexion. This work suggests potential significance of educating CSM patients on maintaining individualized neck positions based on their clinical and radiographic findings.

\section{Abbreviations}

CSM: cervical spondylotic myelopathy; DSSEP: dynamic somatosensory evoked potential; MRI: Magnetic Resonance Imaging; CR: Compression ratios at the compressed site in MRI axial images; El: DSSEP ExtensionImproved group; EN: DSSEP Extension-Nonimproved group; FI: DSSEP Flexion-Improved group; FN: DSSEP FlexionNonimproved group

\section{Declarations}

\section{Ethics approval and consent to participate}

The study was registered as "Dynamic Somatosensory Evoked Potentials for the diagnostic and prognostic evaluation for Cervical Spondylotic Myelopathy" and was approved by the institutional review board (IEC) for clinical and animal trials of the First Affiliated Hospital of Sun Yat-sen University on April 30th, 2020. The trial registration number is: [2020]151. We used only recorded medical data; the IEC at our center approved the study and waived the requirement for informed consent.

\section{Consent for publication}

Each patient provided informed consent for this publication.

\section{Availability of data and materials}

The datasets generated during the current study are available from the corresponding author on reasonable request.

\section{Competing interests}

The authors declare that they have no competing interests.

\section{Funding}

The study was financially supported by the National Natural Science Foundation of China (No. 32071341), Natural Science Foundation of Guangdong Province (2017A030308004) and Natural Science Foundation of Guangzhou City (201804020011).

\section{Authors' contributions}

ZY and JC were involved in analysis and interpretation of data, as well as in drafting and revising the manuscript. $X C$ revised it critically for important intellectual content. XP and XZ made substantial contributions to conception and design of the study, and gave final approval of the version to be published. ZZ, DX, and YC were involved in acquisition of data. All authors read and approved the final manuscript.

\section{Acknowledgements}

Not applicable 


\section{References}

1. Olsson SE: The dynamic factor in spinal cord compression; a study on dogs with special reference to cervical disc protrusions. J Neurosurg 1958, 15(3):308-321.

2. Muhle C, Weinert D, Falliner A, Wiskirchen J, Metzner J, Baumer M, Brinkmann G, Heller M: Dynamic changes of the spinal canal in patients with cervical spondylosis at flexion and extension using magnetic resonance imaging. Invest Radio/ 1998, 33(8):444-449.

3. Ordway NR, Seymour RJ, Donelson RG, Hojnowski LS, Edwards WT: Cervical flexion, extension, protrusion, and retraction. A radiographic segmental analysis. Spine (Phila Pa 1976) 1999, 24(3):240-247.

4. Nardone R, Holler Y, Brigo F, Frey VN, Lochner P, Leis S, Golaszewski S, Trinka E: The contribution of neurophysiology in the diagnosis and management of cervical spondylotic myelopathy: a review. Spinal Cord 2016, 54(10):756-766.

5. Qi Q, Huang S, Ling Z, Chen Y, Hu H, Zhan P, Zhang B, Zou X, Peng X: A New Diagnostic Medium for Cervical Spondylotic Myelopathy: Dynamic Somatosensory Evoked Potentials. World Neurosurg 2020, 133:e225-e232.

6. Yu Z, Lin K, Chen J, Chen KH, Guo W, Dai Y, Chen Y, Zou X, Peng X: Magnetic resonance imaging and dynamic Xray's correlations with dynamic electrophysiological findings in cervical spondylotic myelopathy: a retrospective cohort study. BMC Neurol 2020, 20(1):367.

7. Morishita Y, Maeda T, Ueta T, Naito M, Shiba K: Dynamic somatosensory evoked potentials to determine electrophysiological effects on the spinal cord during cervical spine extension: clinical article. J Neurosurg Spine 2013, 19(3):288-292.

8. Jha SC, Miyazaki M, Tsumura H: Kinetic change of spinal cord compression on flexion-extension magnetic resonance imaging in cervical spine. Clin Neurol Neurosurg 2018, 174:86-91.

9. Zhang L, Zeitoun D, Rangel A, Lazennec JY, Catonné Y, Pascal-Moussellard H: Preoperative Evaluation of the Cervical Spondylotic Myelopathy With Flexion-Extension Magnetic Resonance Imaging. Spine (Phila Pa 1976) 2011, 36(17):E1134-E1139.

10. Stamm S, McClellan JW, 3rd, Knierim A, Suiter IP, Riew KD: Dynamic MRI Reveals Soft-Tissue Compression Causing Progressive Myelopathy in Postlaminectomy Patients: A Report of Three Cases. JBJS Case Connect 2013, 3(1):e17.

11. Benzel EC, Lancon J, Kesterson L, Hadden T: Cervical laminectomy and dentate ligament section for cervical spondylotic myelopathy. Journal of spinal disorders 1991, 4(3):286-295.

12. Qi Q, Huang S, Ling Z, Chen Y, Hu H, Zhang P, Zhang B, Zou X, Peng X: A new diagnostic medium for cervical spondylotic myelopathy: Dynamic somatosensory evoked potentials. World Neurosurg 2019.

13. Nuwer MR, Aminoff M, Desmedt J, Eisen AA, Goodin D, Matsuoka S, Mauguiere F, Shibasaki H, Sutherling W, Vibert JF: IFCN recommended standards for short latency somatosensory evoked potentials. Report of an IFCN committee. International Federation of Clinical Neurophysiology. Electroencephalogr Clin Neurophysio/ 1994, 91(1):6-11.

14. Li Z, Xue Y, He D, Tang Y, Ding H, Wang Y, Zong Y, Zhao Y: Extensive laminectomy for multilevel cervical stenosis with ligamentum flavum hypertrophy: more than 10 years follow-up. Eur Spine J 2015, 24(8):1605-1612.

15. Muhle C, Wiskirchen J, Brinkmann G, Falliner A, Weinert D, Reuter M, Heller M: Kinematic MRI in degenerative cervical spine changes. Rofo 1995, 163(2):148-154.

16. Miyazaki M, Hong SW, Yoon SH, Morishita Y, Wang JC: Reliability of a magnetic resonance imaging-based grading system for cervical intervertebral disc degeneration. Journal of spinal disorders \& techniques 2008, 
21(4):288-292.

17. Ohara A, Miyamoto K, Naganawa T, Matsumoto K, Shimizu K: Reliabilities of and correlations among five standard methods of assessing the sagittal alignment of the cervical spine. Spine (Phila Pa 1976) 2006, 31(22):2585-2591; discussion 2592.

18. Milligan J, Ryan K, Fehlings M, Bauman C: Degenerative cervical myelopathy: Diagnosis and management in primary care. Can Fam Physician 2019, 65(9):619-624.

19. Muhle C, Wiskirchen J, Weinert D, Falliner A, Wesner F, Brinkmann G, Heller M: Biomechanical aspects of the subarachnoid space and cervical cord in healthy individuals examined with kinematic magnetic resonance imaging. Spine (Phila Pa 1976) 1998, 23(5):556-567.

20. Muhle C, Metzner J, Weinert D, Falliner A, Brinkmann G, Mehdorn MH, Heller M, Resnick D: Classification system based on kinematic MR imaging in cervical spondylitic myelopathy. AJNR Am J Neuroradio/ 1998, 19(9):17631771.

21. Hattou L, Morandi X, Le Reste PJ, Guillin R, Riffaud L, Henaux PL: Dynamic cervical myelopathy in young adults. Eur Spine J 2014, 23(7):1515-1522.

22. Henderson FC, Geddes JF, Vaccaro AR, Woodard E, Berry KJ, Benzel EC: Stretch-associated injury in cervical spondylotic myelopathy: new concept and review. Neurosurgery 2005, 56(5):1101-1113; discussion 1101-1113.

23. Tetreault LA, Kopjar B, Vaccaro A, Yoon ST, Arnold PM, Massicotte EM, Fehlings MG: A clinical prediction model to determine outcomes in patients with cervical spondylotic myelopathy undergoing surgical treatment: data from the prospective, multi-center AOSpine North America study. J Bone Joint Surg Am 2013, 95(18):16591666.

24. Zeitoun D, El Hajj F, Sariali E, Catonné Y, Pascal-Moussellard H: Evaluation of spinal cord compression and hyperintense intramedullary lesions on T2-weighted sequences in patients with cervical spondylotic myelopathy using flexion-extension MRI protocol. The Spine Journal 2015, 15(4):668-674.

25. Hayashi T, Wang JC, Suzuki A, Takahashi S, Scott TP, Phan K, Lord EL, Ruangchainikom M, Shiba K, Daubs MD: Risk factors for missed dynamic canal stenosis in the cervical spine. Spine (Phila Pa 1976) 2014, 39(10):812819.

26. Zhong G, Buser Z, Lao L, Yin R, Wang JC: Kinematic relationship between missed ligamentum flavum bulge and degenerative factors in the cervical spine. The spine journal : official journal of the North American Spine Society 2015, 15(10):2216-2221.

27. Tamai K, Grisdela P, Jr., Romanu J, Paholpak P, Buser Z, Wang JC: Kinematic characteristics of patients with cervical imbalance: a weight-bearing dynamic MRI study. Eur Spine J 2019, 28(5):1200-1208.

28. Chen CJ, Hsu HL, Niu CC, Chen TY, Chen MC, Tseng YC, Wong YC, Wang LJ: Cervical degenerative disease at flexion-extension MR imaging: prediction criteria. Radiology 2003, 227(1):136-142.

\section{Figures}



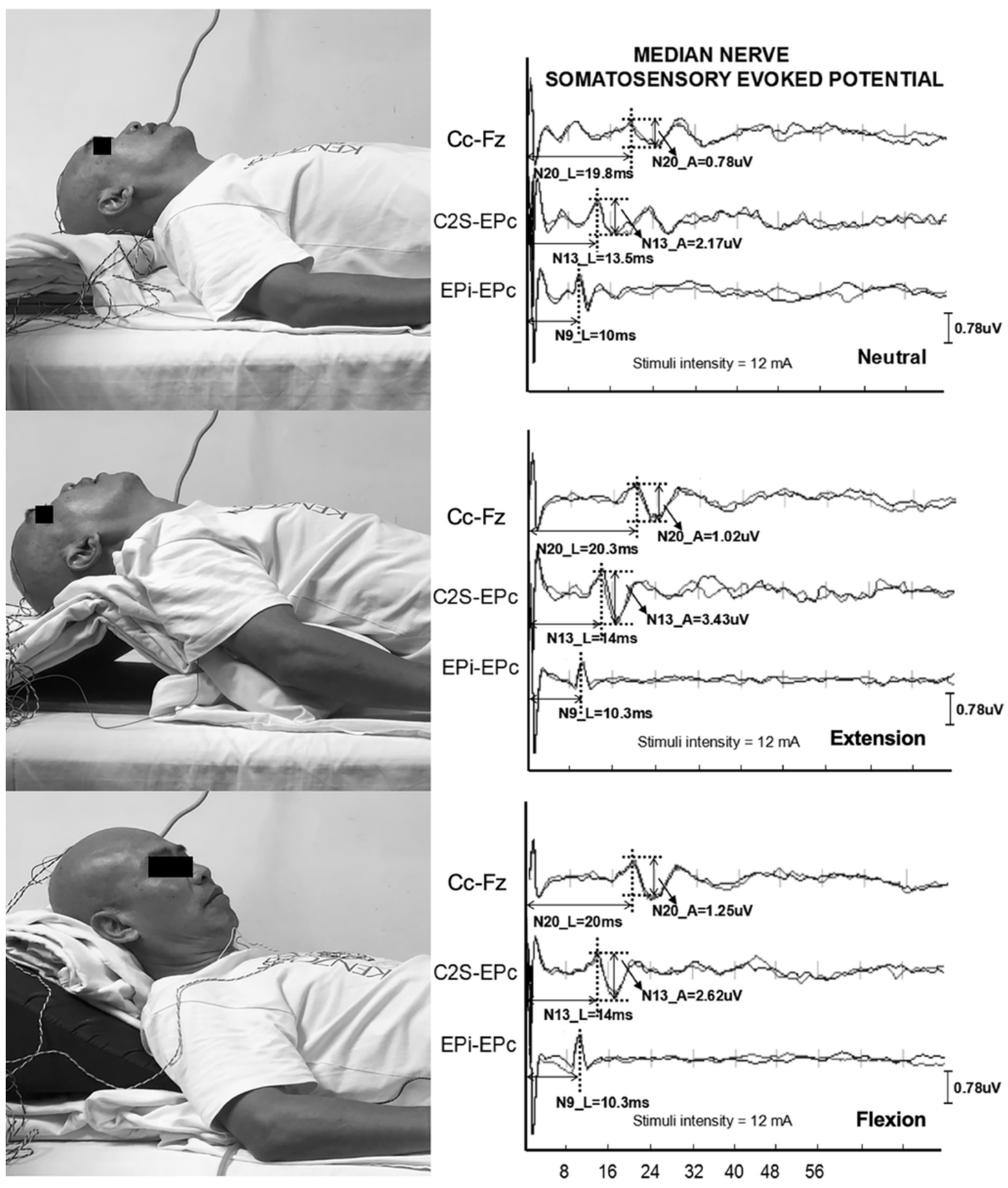

Figure 1

DSSEP illustration and of a 51-year-old male in the El group. Left: Cervical spine in neutral, $20^{\circ}$ extension and $35^{\circ}$ flexion positions. Right: DSSEP results of the left median nerve of this CSM patient. The latencies of N9, N13 and N20, amplitudes of N13 and N20 are shown in the figure. 


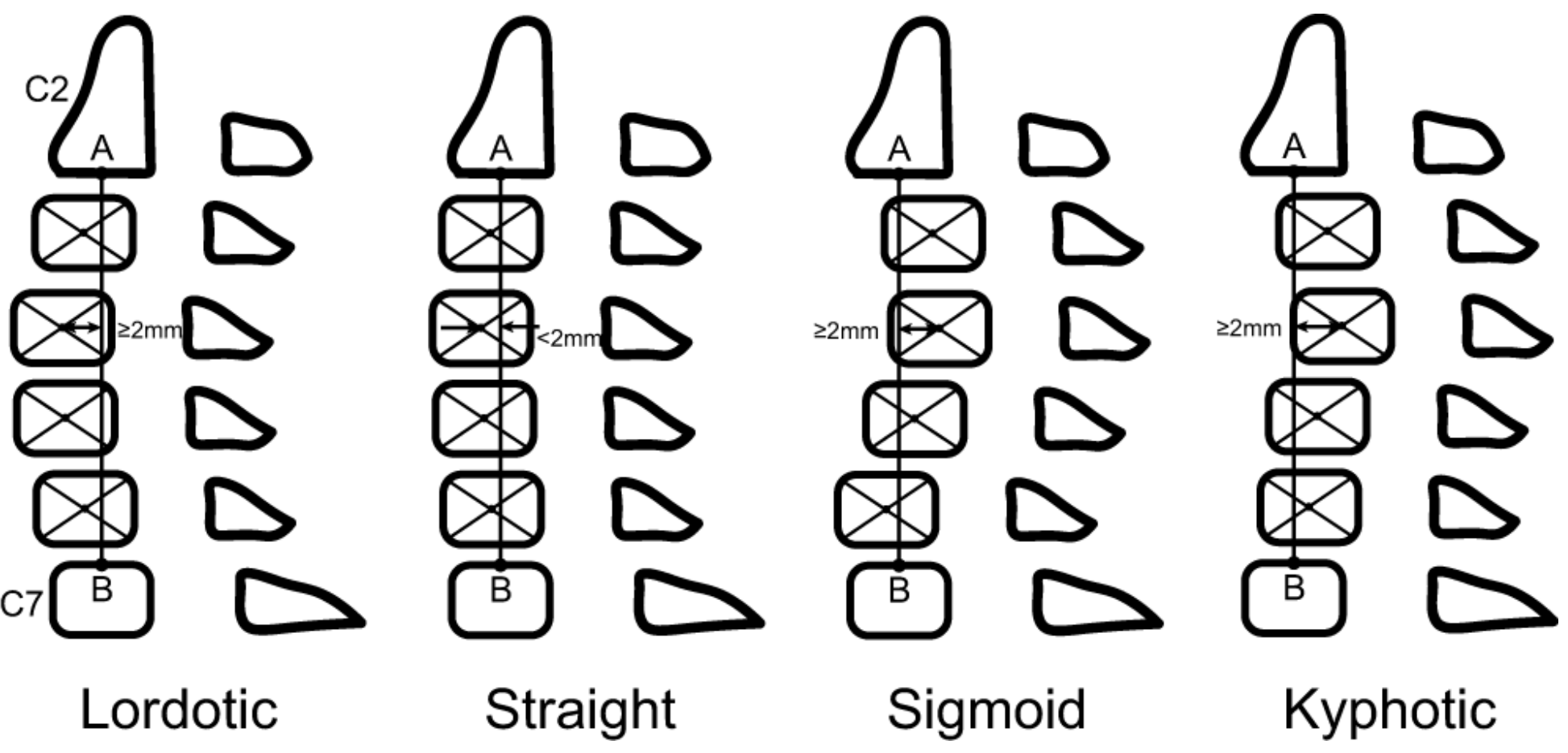

Figure 2

Cervical alignment types (modified Toyama method[17]): A line connecting the mid-points of the inferior margin of C2 and the superior margin of C7 was constructed. Lordotic group: all centroids are anterior to the line and the distance between at least one centroid and the line is $2 \mathrm{~mm}$ or more; Straight group: the distance between the line and each centroid is less than $2 \mathrm{~mm}$; Sigmoid group: some centroids are anterior to and some posterior to the line and the distance between the line and at least one centroid is $2 \mathrm{~mm}$ or more; Kyphotic group: all the centroids are posterior to the line and the distance between at least one centroid and the line is $2 \mathrm{~mm}$ or more.
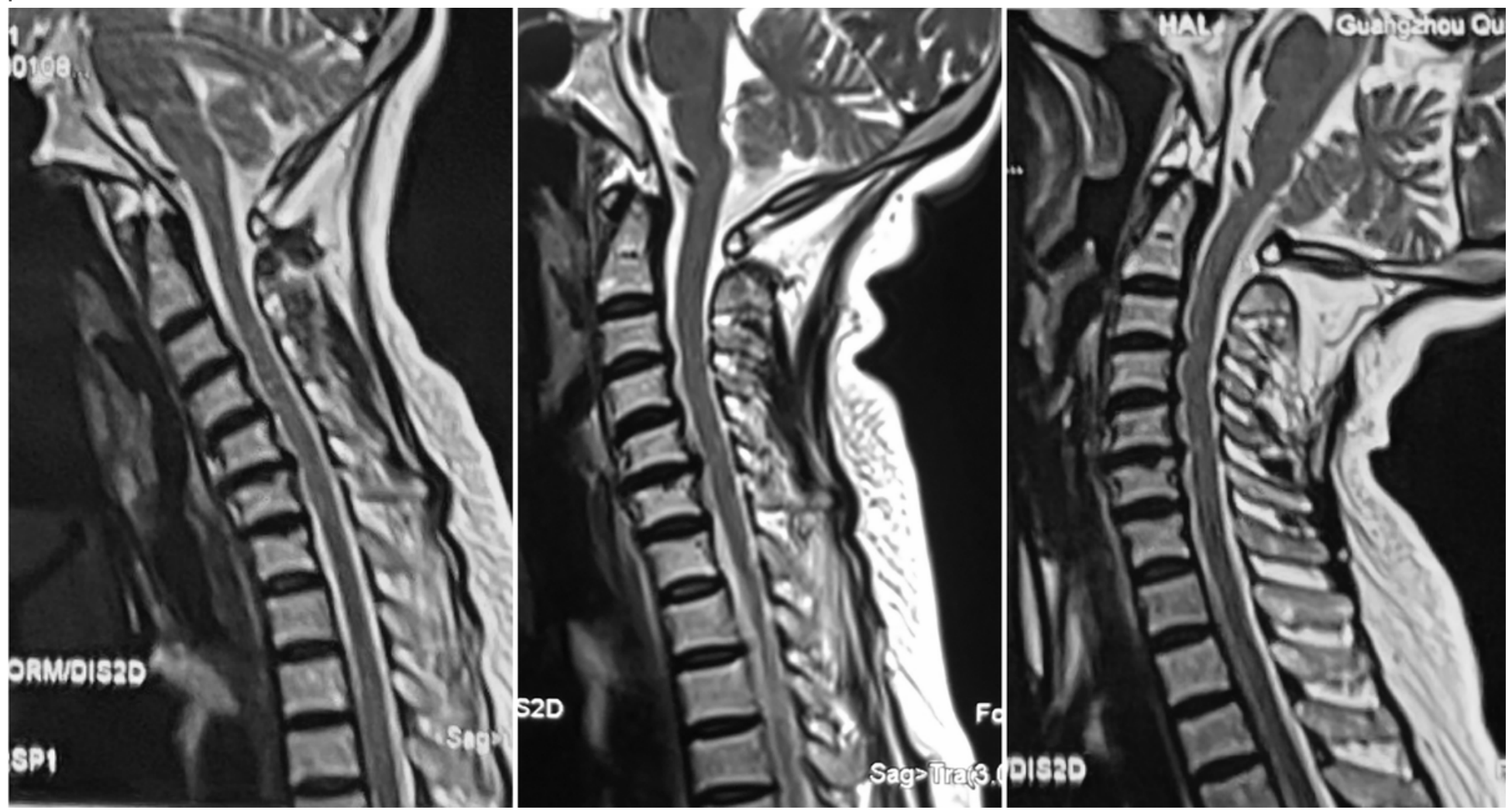
Figure 3

Dynamic MR images of a patient with deteriorated DSSEP at extension and unchanged DSSEP at flexion. From left to right were cervical flexion, neutral and extension positions. Upon a neutral position, the patient had lordotic cervical alignment, as well as protruded C5/6 and herniated C3/4 and C4/5 segments. The Mühle stenosis grade of this patient was Grade 2. Upon flexion, the spinal cord compression did not change significantly. Upon extension, all three segments narrowed significantly and thus exacerbated the spinal cord compression.
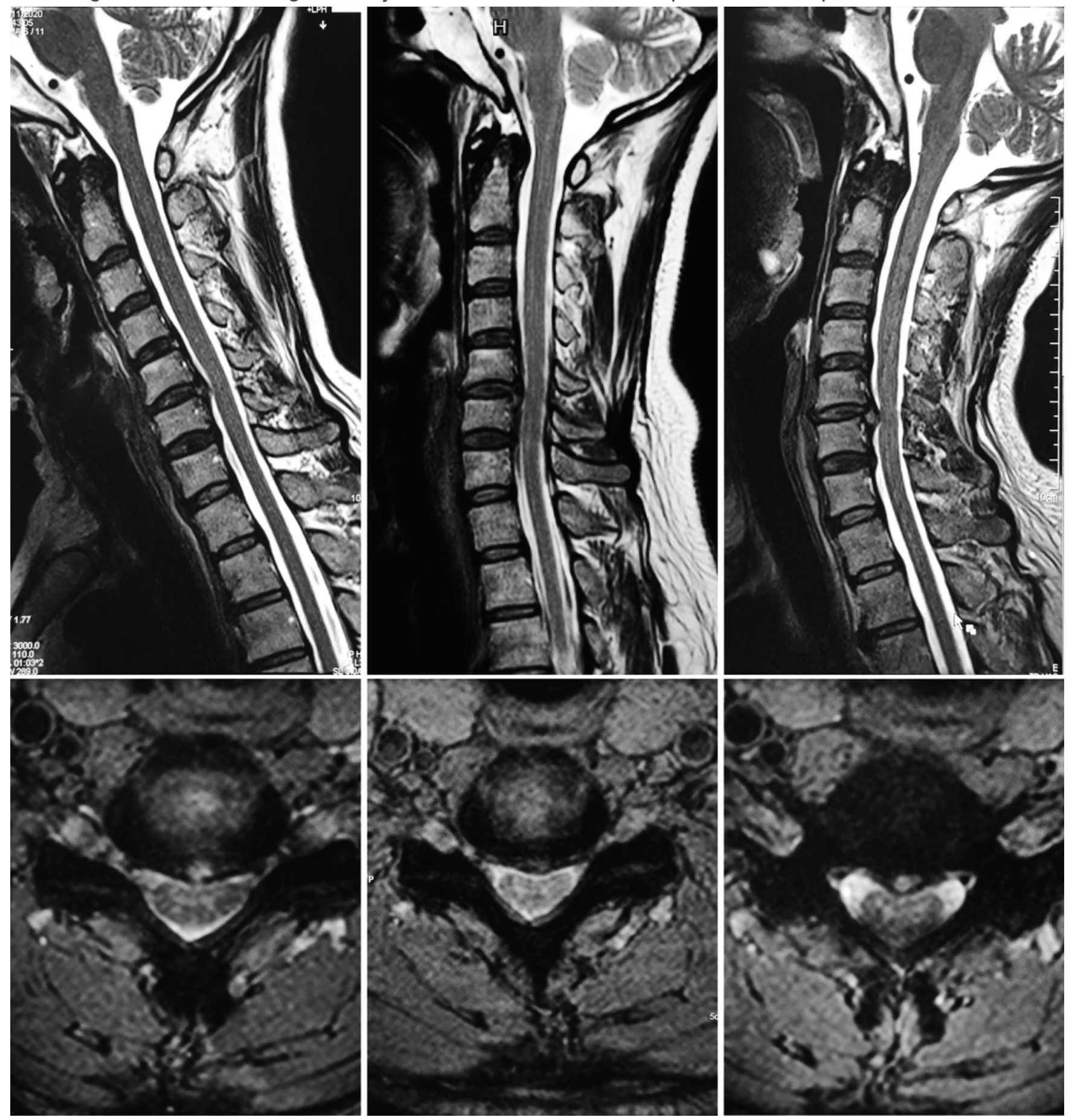

Figure 4

Dynamic MR images of a patient with improved DSSEP at extension and deteriorated DSSEP at flexion. From left to right were cervical flexion, neutral and extension positions. Upon neutral position, this patient had a straight cervical 
alignment and a single protruded C5/6 segment. The Mühle stenosis grade of this patient was Grade 1. Upon flexion, the spinal cord was longitudinally stretched and draped forward. The cerebral fluid in front of the spinal cord was narrower in the axial image. Upon extension, although the diameter of his cervical canal did not change significantly, the spinal cord was longitudinally relaxed and draped backward and, therefore, ameliorated the anterior compression to some extent. The cerebral fluid in front of the spinal cord was wider in the axial image of the extension position. 